Res., Soc. Dev. 2019; 8(9):e50891327

ISSN 2525-3409 | DOI: http://dx.doi.org/10.33448/rsd-v8i9.1327

\title{
Análise do escoamento em poços horizontais injetores completados com a técnica de furação diversiva
}

\section{Analysis of the flow in horizontal injector wells with profile equalization completion Análisis del flujo en pozos horizontales inyectores con agujeros para igualar el perfil de flujo}

Recebido: 20/06/2019 | Revisado: 21/06/2019 | Aceito: 26/06/2019 | Publicado: 27/06/2019

\section{Isabela Silva Mantegazini}

ORCID: https://orcid.org/0000-0001-5677-7378

Universidade Federal do Espírito Santo, Brasil

E-mail: isabelasmantegazini@gmail.com

Oldrich Joel Romero

ORCID: https://orcid.org/0000-0001-5774-6987

Universidade Federal do Espírito Santo, Brasil

E-mail: oldrich.romero@ufes.br

\section{Resumo}

A depender de sua magnitude, as perdas de carga devido ao atrito podem influenciar significativamente o perfil de fluxo em poços horizontais injetores. Perfis de fluxo nãouniformes são responsáveis pela perda da injetividade e pela diminuição da eficiência de varrido, que são efeitos indesejados na recuperação de petróleo. Neste contexto, a técnica de furação diversiva, analisada neste trabalho, é proposta para uniformizar o perfil de fluxo através da distribuição diferenciada dos furos ao longo do liner, que é um tubo metálico utilizado na completação. O presente trabalho utiliza uma tubulação horizontal com furação diferenciada para analisar o escoamento em poços horizontais injetores completados com a técnica de furação diversiva, destacando os efeitos das forças inerciais e viscosas sobre o perfil de perda de carga e, consequentemente, sobre o perfil de fluxo. A solução das equações é obtida com auxílio do software da família Ansys 15.0 para cinco cenários com diferentes viscosidade do fluido injetado. Os resultados demonstram que o perfil de fluxo utilizando a furação diversiva do liner segue a tendência da perda de pressão ao longo da seção horizontal do poço. Observa-se também que o domínio das forças inerciais resultou em perfis de fluxo mais uniformes e, por consequência, maior injetividade, enquanto que o domínio das forças viscosas resultou em baixa influência dos efeitos hidráulicos. 
Res., Soc. Dev. 2019; 8(9):e50891327

ISSN 2525-3409 | DOI: http://dx.doi.org/10.33448/rsd-v8i9.1327

Palavras-chave: Poços horizontais; Perda de carga; Furação diversiva; CFD.

\begin{abstract}
Pressure losses due to friction can significantly influence the flux profile in horizontal injector wells, depending on their magnitude. Non-uniform flux profiles are responsible for the loss of injectivity and for the decrease in sweep efficiency, which are undesirable effects for oil recovery. In this context, the divergent perforation, or profile equalization completion, is a technique able to uniformize the flux profile by the differentiated distribution of the holes on the completion liner. This study used simulations of the flow in a pipe with differentiated perforation to analyze the flow in horizontal injector wells completed with the divergent perforation technique and the effect of both inertial and viscous forces on the pressure loss profile and, consequently, on the flux profile. The simulations realized at the Ansys 15.0 family software demonstrated that the flux profile follows the pressure loss trend on the horizontal section of the well. It was observed that the dominance of inertial forces resulted in more uniform flow profiles and so in better injectivity, while the dominance of the viscous forces resulted in the low influence of the hydraulic effects.
\end{abstract}

Keywords: Horizontal wells; Pressure drop; Profile equalization completion; CFD.

\title{
Resumen
}

Las pérdidas de presión debido a la fricción pueden influenciar significativamente el perfil de flujo en pozos horizontales inyectores, dependiendo de su magnitud. Los perfiles de flujo no uniformes son responsables de la pérdida de la inyectividad y la disminución de la eficiencia de barrido, que son efectos no deseados para la recuperación de petróleo. En este contexto, la técnica de perforación diversiva es capaz de uniformizar el perfil de flujo a través de la distribución diferenciada de los agujeros en la tubería de completación. Este estudio utiliza la simulación del flujo en un tubo con diversos agujeros en la pared para analizar el flujo en pozos horizontales inyectores completados con la técnica mencionada. Los efectos de las fuerzas inerciales y viscosas sobre el perfil de pérdida de carga y, consecuentemente, sobre el perfil de flujo son estudiados. Las simulaciones realizadas en el software de la familia Ansys 15.0 demostraron que el perfil de flujo sigue la tendencia de la pérdida de presión a lo largo de la sección horizontal del pozo. Se observó que el dominio de las fuerzas inerciales resultó en perfiles de flujo más uniformes y, por consiguiente, mayor inyectividad, mientras que el dominio de las fuerzas viscosas resultó en baja influencia de los efectos hidráulicos. 
Res., Soc. Dev. 2019; 8(9):e50891327

ISSN 2525-3409 | DOI: http://dx.doi.org/10.33448/rsd-v8i9.1327

Palabras clave: Pozos horizontales; Reducción de presión; Agujeros para flujo constante; CFD.

\section{Introdução}

O cenário atual da matriz energética mundial evidencia o crescimento da utilização de fontes renováveis de energia. No entanto, o petróleo é o protagonista uma vez que sua versatilidade e sua eficiência o tornam insubstituível em suas funcionalidades (British Petroleum, 2018). Além de ser fonte de energia, os derivados do petróleo são utilizados em todo tipo de indústria, como matéria-prima ou como outro insumo de produção (Vale, 2010).

Em contraponto ao aumento da demanda mundial, as empresas petrolíferas encaram grandes desafios no que diz respeito à finitude do petróleo como recurso: ele demora milhões de anos para ser formado sob condições bem específicas e é consumido em poucos anos. Ainda, devido à depleção e ao trapeamento na rocha porosa, nem todo o petróleo descoberto é recuperável, mesmo após a utilização dos métodos artificiais e especiais, respectivamente.

Segundo Vale (2010), as ações mais comuns frente a este tipo de obstáculo baseiam-se em aumentar o contingente de reservas, através da busca por mais campos de petróleo, ou em maximizar o fator de recuperação. Esta última ação foi catalogada pela Agência Nacional do Petróleo, Gás Natural e Bicombustíveis (ANP), no $\S 3^{\circ}$ do art. $6^{\circ}$ da Resolução ANP $n^{\circ}$ 17/2015, como o objetivo das empresas com relação à estratégia de explotação a ser adotada diante da elaboração do Plano de Desenvolvimento. Esta estratégia, em conjunto com as soluções tecnológicas que a possibilitam, deve ser continuamente reavaliada de forma que o objetivo seja alcançado (ANP, 2017).

Neste contexto, o desenvolvimento da tecnologia de poços horizontais utilizados para a injeção de fluidos permitem que uma porção maior do reservatório seja atingido, em comparação aos poços verticais, melhorando a injetividade e, por consequência, a recuperação do campo (Joshi, 1991). Porém, a depender da magnitude da perda de pressão no interior do poço horizontal, o perfil de fluxo de injeção pode não ser uniforme ao longo de sua extensão. Para Fernandes, Silva e Bedrikovetsky (2006), este problema, que ocorre quando a tubulação horizontal (liner) tem furos igualmente espaçados, leva a baixas eficiências de varrido, causando efeito contrário ao desejado para a recuperação.

Para contornar o problema exposto através da distribuição diferenciada de área aberta ao fluxo na extensão do liner é proposto a furação diversiva, que é uma técnica capaz de promover a uniformização do perfil de fluxo nos poços (Fernandes, Silva \& Bedrikovetsky, 
Res., Soc. Dev. 2019; 8(9):e50891327

ISSN 2525-3409 | DOI: http://dx.doi.org/10.33448/rsd-v8i9.1327

2006). O intuito desta técnica é alocar maior área aberta ao fluxo nas regiões de menor diferencial de pressão entre o poço e a formação. Cabe ressaltar que a furação diversiva é utilizada com sucesso na uniformização do perfil de fluxo não apenas de poços injetores, mas também em poços produtores e principalmente em campos brasileiros (Fernandes et al., 2006; Petrobras, 2014).

Assim, o objetivo principal deste trabalho é analisar a sensibilidade do escoamento em poços horizontais injetores completados com a técnica de furação diversiva.

\subsection{Tecnologia de poços horizontais}

Por definição, poços horizontais são aqueles perfurados paralelamente ao plano de estratificação normal do reservatório (Joshi, 1991). No caso de reservatórios com estratificação horizontal, o processo de perfuração do poço é iniciado verticalmente, seguindo até a região de desvio, denominada kick off point (KOP), identificada na Figura 1. O poço, então, começa a ser desviado até que se atinja a disposição horizontal. A seção horizontal do poço se comunica com o reservatório por meio da completação, no caso deste trabalho, um liner perfurado.

Figura 1 - Geometria típica de um poço horizontal mostrando a parte vertical e o KOP - kick off point.

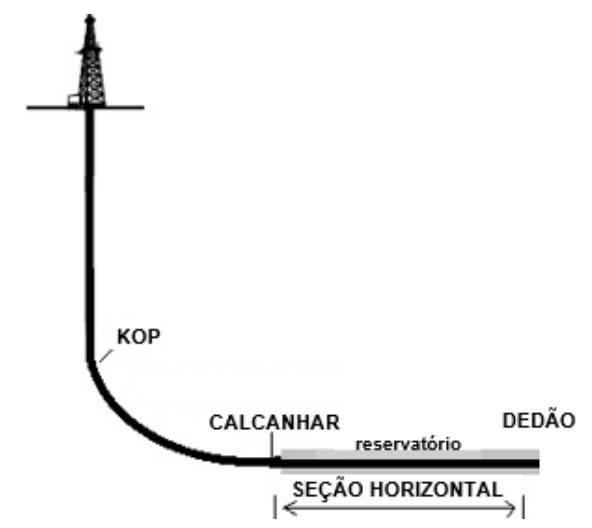

Fonte: adaptado de Art of Directional Drilling (2015).

A geometria típica de um poço horizontal é usualmente comparada à de um pé: a região mais próxima ao KOP é semelhante a um calcanhar e a extremidade final do poço configura um dedão (Santos, 2014). A utilização de poços horizontais constitui uma prática relativamente recente, em comparação ao início das atividades de perfuração, tendo a tecnologia se desenvolvido de forma relevante em meados dos anos 1970, após muitas tentativas experimentais (Brito, 2008). Desde então, diversas vantagens decorrentes da aplicação de poços horizontais, tanto como produtores quanto como injetores, foram observadas. 
Joshi (1991) afirmou que a disposição horizontal melhora a eficiência dos poços produtores e injetores, através do aumento de suas áreas de contato com o reservatório, sendo este o maior propósito da utilização dos poços horizontais.

Inglis (1987) explicou que os poços horizontais podem ser utilizados em conjunto com os métodos especiais de recuperação, citando como exemplo a aplicação de uma variação do método Steam Assisted Gravity Drainage (SAGD) no Canadá. Joshi (1991) relatou a aplicação dos poços horizontais também em operações de injeção de água e de solução polimérica e em métodos miscíveis. Para um poço injetor, o aumento da área de contato com o reservatório acarreta no aumento da injetividade, que é um dos grandes desejos para a recuperação, além do aumento da eficiência de varrido (Guilhermino, 2013).

As vantagens observadas e o desenvolvimento de novas tecnologias fizeram com que a utilização dos poços horizontais aumentasse nas últimas décadas (Guilhermino, 2013; Vale, 2010). Consequentemente, as pesquisas voltadas para o método tornaram-se cada vez mais recorrentes (Oliveira, 2011). Tais pesquisas estudam o desempenho dos poços para torná-los ainda mais eficientes e viáveis economicamente, uma vez que, de acordo com Joshi (1991), as operações relacionadas à sua instalação são um tanto dispendiosas, a depender das técnicas de perfuração e de completação utilizadas.

\subsection{Perda de carga em poços horizontais}

A perda de carga no interior do poço horizontal influencia diretamente o seu desempenho. Se os efeitos da perda de carga são desprezados tem-se o modelo de condutividade infinita, se são considerados resulta no modelo de condutividade finita (Vale, 2010).

A queda de pressão $\Delta P_{\text {prod }}=P_{\text {res }}-P_{t u b}(x)$, entre o reservatório $P_{\text {res }}$ e o interior do poço horizontal produtor $P_{t u b}(x)$, é constante no modelo de condutividade infinita. $\mathrm{Na}$ condutividade finita o $\Delta P_{\text {prod }}$ é maior perto do calcanhar e cada vez menor no dedão do poço (veja Figura 1). Este comportamento se acentua com o aumento da vazão de produção.

O perfil de fluxo para a condutividade infinita possui formato abaulado e simétrico. Nas extremidades, ou seja, no dedão e no calcanhar, a vazão aumenta consideravelmente, porque estas regiões estão expostas a uma maior área de drenagem do reservatório (Ozkan, Sarica \& Haci, 1999; Rosa, 2017).

Em poços horizontais produtores o escoamento no interior do poço ocorre no sentido do dedão para o calcanhar do poço, fazendo com que a pressão diminua também neste 
sentido, devido à perda de carga. Deste modo, a pressão na região do calcanhar é menor do que a pressão na região do dedão. Como a pressão média do reservatório $\left(P_{r e s}\right)$ é maior do que a pressão em qualquer ponto interior do liner $\left(P_{t u b}(x)\right)$, o fluxo para o interior do poço produtor é maior perto do calcanhar.

No caso de poços horizontais injetores de comprimento $L$ o escoamento ocorre no sentido do calcanhar para o dedão do poço, ao longo da coordenada $x$, com redução da perda de carga neste mesmo sentido. A pressão no interior do poço $\left(P_{t u b}(x)\right)$ diminui ao longo do liner, ou seja, a pressão na região do calcanhar é maior do que a pressão na região do dedão $\left(P_{t u b}(x=0)>P_{t u b}(x=L)\right)$. Assim, como a pressão média do reservatório $\left(P_{r e s}\right)$ é menor do que a pressão em qualquer ponto do liner $\left(P_{t u b}(x)>P_{r e s}\right)$, o fluxo para o exterior do poço é maior perto do calcanhar, configuração idêntica ao caso do produtor. De forma semelhante à produção, na injeção tem-se a queda de pressão $\Delta P_{i n j}=P_{t u b}(x)-P_{r e s}$, que diminui à medida que o fluido se afasta do calcanhar, comportamento representado na Figura 2.

Figura 2 - Variação da pressão $P_{t u b}(x)$ no interior de um poço horizontal injetor e pressão média no reservatório $P_{\text {res }}$. O escoamento ocorre no sentido crescente do comprimento do poço.

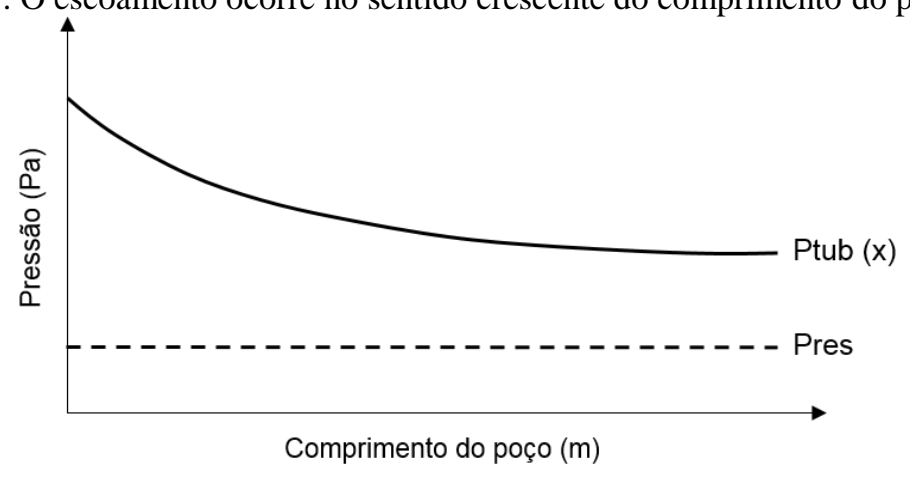

Fonte: Autores (2019).

Segundo Vale (2010), a adoção adequada de um dos modelos depende da ordem de grandeza entre a pressão no poço e no reservatório. Ozkan et al. (1999) explicam que a condutividade infinita é adequado quando a magnitude da queda de pressão no poço é muito menor do que a magnitude da queda de pressão no reservatório, podendo, então, ser desprezada. Isso significa que os efeitos hidráulicos no poço eram desconsiderados. A adoção equivocada do modelo de condutividade pode levar a consequências diretas como a menor confiabilidade no tocante à previsão da produtividade e ao tempo de irrupção de água ou de gás no poço e a discrepância entre os resultados da simulação e a realidade (Rosa, 2017).

Dikken (1990) foi o pioneiro no uso do modelo de condutividade finita apresentando um modelo semianalítico para o cálculo da produtividade de um poço horizontal com escoamento turbulento (Landman \& Goldthorpe, 1991). Desde então, a perda de carga por 
atrito passou a ser melhor considerada por pesquisadores como Ozkan et al. (1999), Penmatcha, Arbabi e Aziz (1999) e Vicente et al. (2003).

Ozkan et al. (1999) e Penmatcha et al. (1999) concluíram que na época a condutividade infinita era muito utilizada. Ao mesmo tempo, os autores propuseram modelos semianalíticos para determinar o efeito da perda de carga sobre a produtividade, uma vez que o modelo de condutividade infinita não representa a maior parte da realidade observada nos campos.

Vicente et al. (2003) também estudaram a influência que diversos parâmetros exercem sobre a perda de carga, ressaltando que seus efeitos sobre o escoamento no poço e sobre a produtividade não devem ser negligenciados. Segundo os autores, o modelo de condutividade infinita superestima a produtividade em poços longos ou de pequenos diâmetros, com fluidos de altas viscosidades ou a altas vazões, entre outros parâmetros.

\subsection{Furação diversiva}

Uma das técnicas para diminuir a perda de carga consiste em alterar o padrão de distribuição dos furos no liner, resultando na técnica denominada furação diversiva estudada por autores como Landman e Goldthorpe (1991), Hansen e Nederveen (2002), Fernandes et al. (2006), Oliveira, Magalhães e Martins (2006) e Santos (2014).

A técnica de furação diversiva consiste em projetar o liner (ou tubulação que permite o escoamento dos fluidos) de forma que os furos fiquem mais concentrados na região do dedão do poço horizontal resultando em maior área aberta ao fluxo nesta região. O diferencial de pressão entre este trecho do poço e o reservatório é menor, em comparação à região do calcanhar, devido à perda de carga na extensão horizontal do poço. Desta forma, promove-se o aumento e a diminuição da vazão nos locais onde ela costumava ser menor e maior, respectivamente, como demonstrado na comparação entre os perfis de fluxo para um liner sem e com furação diversiva da Figura 3. O perfil de fluxo ao longo do liner torna-se mais uniforme com a furação diversiva (Fernandes et al., 2006).

Landman e Goldthorpe (1991) discutiram a técnica elaborando um modelo matemático para investigação do efeito da distribuição da furação sobre a produtividade do poço horizontal.

Hansen e Nederveen (2002) relataram que a uniformização do fluxo permitiu que o fluido injetado estimulasse todo o trecho horizontal de poços relativamente longos em apenas 
uma etapa de bombeio, reduzindo os custos e a duração das operações de acidificação na Dinamarca.

Figura 3 - Perfis de fluxo para um liner sem e com furação diversiva no trecho horizontal de um poço produtor. Este comportamento é também observado em um poço injetor.

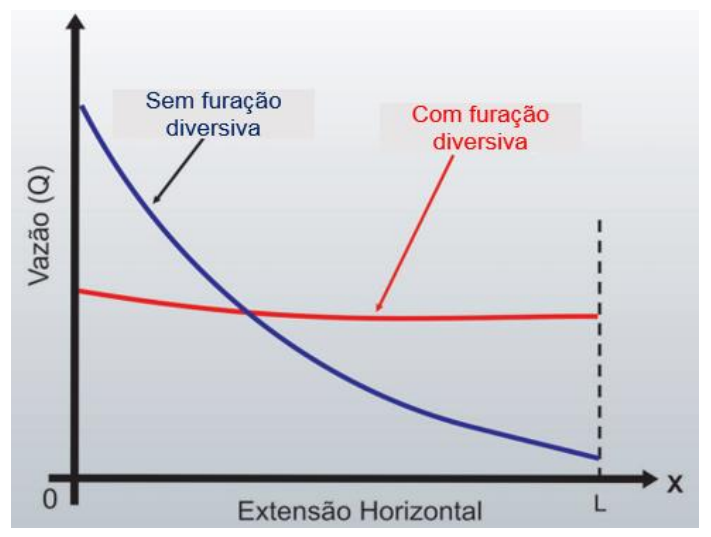

Fonte: adaptado de Fernandes et al. (2006).

Fernandes et al. (2006) formularam o cálculo explícito da distribuição dos furos através de um modelo matemático, o qual foi utilizado no projeto de liners da Petrobras com aplicação bem sucedida em campos operados pela empresa (Petrobras, 2014). A principal expectativa das aplicações é retardar a produção de água, aumentando a vida útil do campo.

Oliveira et al. (2006) estudaram a aplicação do gravel pack em poços horizontais equipados com furação diversiva, utilizando a formulação proposta por Fernandes et al. (2006). Neste caso, as restrições ao escoamento radialmente impostas poderiam gerar uma pressão de bombeio crítica do gravel, especialmente em cenários onde a janela operacional é estreita, arriscando a integridade do poço ou da formação. Dos três casos estudados, apenas um deles atendeu aos critérios de vazão mínima de bombeio e forneceu uniformização satisfatória.

Apesar dos bons resultados em suas aplicações de campo, o cálculo analítico apresenta muitas simplificações, podendo nem sempre fornecer meios adequados para descrever matematicamente os fenômenos físicos. Neste caso, os métodos experimentais conferem maior confiabilidade aos resultados, em comparação aos métodos analíticos. A qualidade dos resultados obtidos neste tipo de abordagem é alta, uma vez que a avaliação geralmente utiliza um protótipo que representa fielmente as características do projeto (Silva, 2017).

Santos (2014) comparou a formulação proposta por Fernandes et al. (2006) a estudos experimentais, concluindo que ela não se adequa a escoamentos com elevado número de Reynolds. Além disso, para poços produtores, foi encontrado que as perdas de carga por atrito aumentam com a vazão, como esperado, enquanto o efeito contrário ocorreu para as perdas de 
Res., Soc. Dev. 2019; 8(9):e50891327

ISSN 2525-3409 | DOI: http://dx.doi.org/10.33448/rsd-v8i9.1327

carga através dos furos. A autora ainda propôs a incorporação, no equacionamento, de um termo capaz de representar os efeitos de aceleração do fluido.

\subsection{Perfil de fluxo em poços horizontais injetores}

A maioria dos autores citados relataram a uniformização de fluxo em poços produtores. Porém, segundo Amaral et al. (2008), a mesma restrição radial aplicada ao escoamento para o interior dos poços horizontais também pode ser aplicada ao escoamento para o seu exterior. Além disso, de acordo com Fernandes et al. (2006) a diferença entre poços produtores e injetores está no sentido contrário do escoamento, tanto no interior do poço quanto no reservatório, o que faz com que a distribuição de fluxo através dos furos seja idêntica para ambos os casos. A técnica de furação diversiva pode, então, ser aplicada tanto em operações de produção quanto em operações de injeção (Oliveira, Magalhães \& Martins, 2006).

Amaral et al. (2008) explicaram que o fluido injetado tende a seguir o caminho de menor resistência para o reservatório. A completação convencional, na qual a furação é uniforme ao longo do liner, oferece baixa resistência ao escoamento radial para o exterior do poço, fazendo com que os efeitos da perda de carga sejam dominantes e injetem o fluido, em sua maior parte, pela região do calcanhar do poço.

A restrição radial ao escoamento, como a fornecida pela furação diversiva, altera o caminho normalmente percorrido pelo fluido injetado, causando a uniformização do fluxo ao longo do liner (Amaral et al., 2008). Desta forma, a uniformização do fluxo ao longo do poço horizontal permite não apenas retardar o surgimento dos cones de água e de gás e melhorar a eficiência de varrido, mas também estimular toda a seção horizontal do poço em uma única etapa de bombeio, melhorando a injetividade (Fernandes et al., 2006).

\subsection{Injetividade em poços horizontais}

A injetividade (I) é a capacidade do poço de injetar o fluido para o reservatório. Matematicamente é a razão entre a vazão de injeção $(q)$ e a diferença entre a pressão de injeção $\left(P_{t u b}\right)$ e a pressão do reservatório $\left(P_{r e s}\right)$, ou seja, $I=q /\left(P_{t u b}-P_{r e s}\right)$. Como se espera, a injetividade depende, além da geometria do poço, de fatores como a viscosidade do fluido produzido e a permeabilidade da formação (Cajazeiras, 2018).

Considerando-se os efeitos da perda de carga causados principalmente pelo atrito menos fluido será injetado no reservatório. Como o diferencial de pressão é diferente ao longo 
do poço horizontal, conforme visualizado na Figura 2, o reservatório não é atingido uniformemente pelo fluido em toda sua extensão, resultando em, por exemplo, baixa eficiência de varrido em operações de acidificação. Além disso, a possibilidade de danos (redução da permeabilidade) no calcanhar do poço é alta. Esta região é importante para manutenção do desempenho dos poços, devendo-se garantir que o dano seja minimizado (Ozkan et al., 1999).

Deste modo, a perda de injetividade se constitui em uma preocupação para a indústria do petróleo, uma vez que leva o poço injetor e toda a operação de injeção a baixas eficiências, independentemente da aplicação. Assim, o estudo da furação diversiva como método para uniformizar a vazão de injeção ao longo do duto, é a motivação para o presente trabalho.

\section{Metodologia}

\subsection{Definição do problema}

A técnica de furação diversiva baseia-se na distribuição diferenciada dos furos no liner de completação. A densidade dos furos diminui à medida que se aproxima do dedão do poço horizontal, conforme demonstrado na Figura 4.

Figura 4 - Furação diversiva representada pela distribuição diferenciada de furos ao longo do trecho de um poço horizontal, objetivando a uniformização de fluxo.

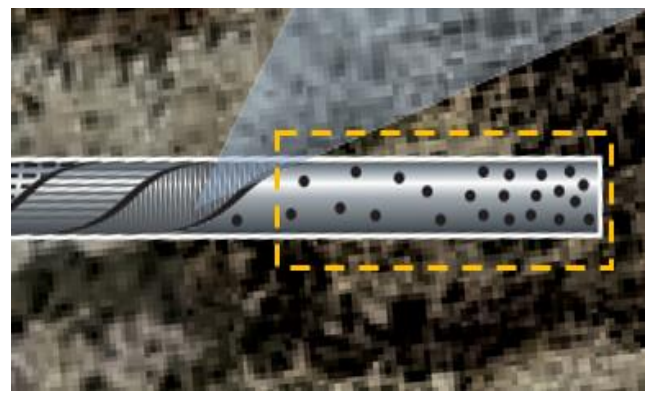

Fonte: adaptado de Petrobras (2014).

O domínio físico do problema estudado é representado na Figura 5 o qual é uma adaptação da região tracejada da Figura 4. Consiste de uma tubulação de comprimento $L=$ $1,5 \mathrm{~m}$, diâmetro $D=6 \mathrm{~cm}$ e espessura igual a $0,8 \mathrm{~cm}$, cujos furos possuem diâmetro $D_{\text {furo }}=$ $1 \mathrm{~cm}$. O fluido injetado no plano esquerdo da tubulação escoa pelo seu interior. Através dos furos localizados na parte intermediaria da tubulação o líquido flui para o ambiente externo, o volume remanescente é impulsionado pelo plano direito para fora da tubulação.

O comprimento $L$ da tubulação foi dividido em três trechos, denominados A, B e C. O trecho A, anterior aos furos, representa $L_{\text {prefuros }}=40 \% L$, o trecho B, no qual os furos estão 
ISSN 2525-3409 | DOI: http://dx.doi.org/10.33448/rsd-v8i9.1327

alocados, representa $L_{\text {furos }}=20 \% L$ e o trecho C, posterior aos furos, representa $L_{\text {posfuros }}=$ 40\%L. Os trechos A e C foram projetados para eliminar os efeitos da imposição das condições de contorno durante o tratamento numérico do problema, as quais serão detalhadas subsequentemente.

Figura 5 - Geometria do problema com as dimensões da tubulação e dos furos, observando-se os trechos (A, B e C) $L_{\text {prefuros }}=0,6 \mathrm{~m}, L_{\text {furos }}=0,3 \mathrm{~m}$ e $L_{\text {posfuros }}=0,6 \mathrm{~m}$, respectivamente.

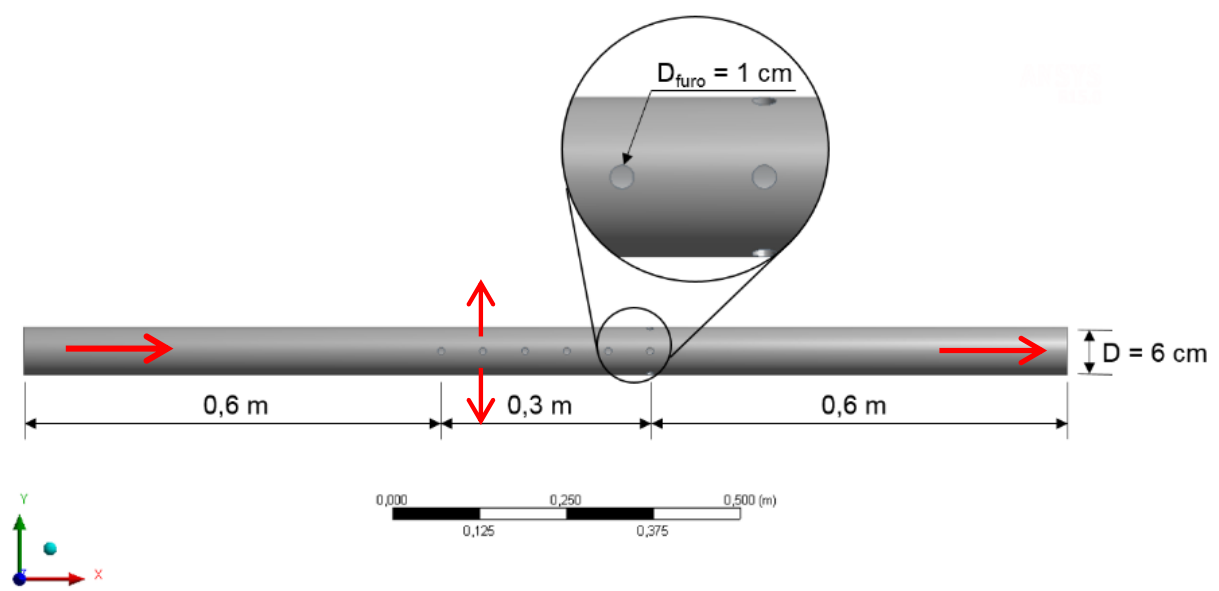

Fonte: Autores (2019).

Neste estudo têm-se 16 furos distribuídos em 6 planos ao longo do trecho B da tubulação, conforme apresentado na Tabela 1. O padrão da distribuição dos furos utilizados baseou-se no estudo de Oliveira et al. (2006).

Tabela 1 - Distribuição da furação em seis planos ao longo do trecho $L_{\text {furos }}=0,3 \mathrm{~m}$, de acordo com sua posição medida a partir da entrada do tubo localizada no lado esquerdo da Figura 5.

\begin{tabular}{|c|c|c|}
\hline Plano & Posição, $m$ & Número de furos \\
\hline 1 & 0,60 & 1 \\
\hline 2 & 0,66 & 1 \\
\hline 3 & 0,72 & 3 \\
\hline 4 & 0,78 & 3 \\
\hline 5 & 0,84 & 3 \\
\hline 6 & 0,90 & 5 \\
\hline
\end{tabular}

A geometria com as dimensões descritas foi adotada buscando-se a adequação com dados reais. No entanto, devido aos fins acadêmicos deste estudo, que visa a ilustração e a análise da aplicação da técnica de furação diversiva em poços horizontais injetores, tais dimensões não representam fielmente a realidade de campo.

Foram simulados cinco cenários para a realização da análise de sensibilidade da influência da viscosidade do fluido injetado, a qual interfere diretamente na magnitude da perda de pressão e, portanto, no perfil de fluxo ao longo da tubulação, representando a parcela das forças viscosas do número de Reynolds. 
ISSN 2525-3409 | DOI: http://dx.doi.org/10.33448/rsd-v8i9.1327

Os dados componentes de cada cenário, apresentados na Tabela 2, foram selecionados de forma a garantir que o fluido incompressível escoasse em regime laminar na tubulação. A massa específica do fluido utilizado nas simulações é igual a $998,2 \mathrm{~kg} / \mathrm{m}^{3}$ na base de dados do Fluent e a velocidade média na entrada é igual a $0,005 \mathrm{~m} / \mathrm{s}$. Os valores de viscosidade utilizados são crescentes e foram consultados em Bertulani (1999), procurando-se manter as condições de escoamento laminar e fluido incompressível à temperatura de $288 \mathrm{~K}$. A simulação com o cenário 5 considerou os mesmos dados do cenário 4 para uma tubulação sem furos.

Tabela 2 - Detalhamento dos cenários estudados.

\begin{tabular}{|c|c|c|c|}
\hline Cenário & Número de furos & Viscosidade, mPa.s & Número de Reynolds \\
\hline 1 & 16 & 0,562 & 532,85 \\
\hline 2 & 16 & 2,48 & 120,75 \\
\hline 3 & 16 & 9,5 & 31,52 \\
\hline 4 & 16 & 20 & 14,97 \\
\hline 5 & 0 & 20 & 14,97 \\
\hline
\end{tabular}

\subsection{Modelagem matemática}

O estudo trata do escoamento tridimensional e monofásico de fluido na seção horizontal de um poço injetor completado com liner de furação diversiva. As propriedades do fluido injetado foram assumidas constantes para cada cenário, estando incluída a condição de fluido incompressível. O escoamento ocorreu de modo laminar e isotérmico. As pressões no meio poroso se encontram em regime permanente ou estável, ou seja, as mesmas são constantes.

Os fatores que tendem a reduzir a pressão no escoamento em um duto são a inclinação, o atrito e a diminuição da área (Fox et al., 2010). Assim, os mecanismos causadores da perda de pressão interna em tubulações são, respectivamente, a mudança de elevação, o atrito e a aceleração, geralmente utilizados para a análise do escoamento, como apresenta a Equação 1.

$\frac{d P}{d L}=\left(\frac{d P}{d L}\right)_{\text {elev }}+\left(\frac{d P}{d L}\right)_{\text {atrito }}+\left(\frac{d P}{d L}\right)_{\text {acc }}$,

onde $P$ é a pressão, $L$ é o comprimento da tubulação e os índices elev, atrito e acc representam os termos referentes à mudança de elevação, ao atrito e à aceleração, respectivamente.

Para poços horizontais as parcelas relativas à elevação e à aceleração são desconsideradas, apenas a relativa ao atrito, calculada através da Equação 2, é incorporada na análise. 
$\left(\frac{d P}{d L}\right)_{\text {atrito }}=\frac{f \rho v^{2}}{2 D}$,

$\rho$ é a massa específica do fluido, $v$ é a velocidade do escoamento, $D$ é o diâmetro interno da tubulação e $f$ é o fator de atrito.

A equação anterior é reescrita como sendo

$\Delta P=\frac{f \rho v^{2} L}{2 D}$

o fator de atrito $f$, de forma geral, depende do número de Reynolds $(R e)$ e da rugosidade relativa. O número de Reynolds $R e$ é obtido de

$R e=\frac{\rho v D}{\mu}$.

já a rugosidade relativa, utilizada para escoamentos turbulentos, é uma relação entre a rugosidade média, que depende basicamente do tipo de material utilizado para confecção e do tempo de utilização da tubulação, e o diâmetro interno D. Para escoamentos laminares (número de Reynolds menor do que 2.300) o fator de atrito é obtido diretamente de

$f=\frac{64}{R e}$.

Das equações anteriores, obtém-se a relação para perda de carga em escoamentos laminares no interior de tubos, apresentada na Equação 6.

$\Delta P=\frac{128 \mu L q}{\pi D^{4}}$,

onde $q$ é a vazão, definida como o produto entre a velocidade média $(v)$ e a área $(A)$ da seção transversal do tubo.

A diminuição da velocidade com o aumento da área pode ser explicada pela equação da continuidade (princípio da conservação da massa), descrita por Fox, Pritchard e McDonald (2010) de acordo com a Equação 7, para escoamentos permanentes, incompressíveis e com viscosidade constante.

$\frac{\partial u}{\partial x}+\frac{\partial v}{\partial y}+\frac{\partial w}{\partial z}=0$,

onde u, v e w são as velocidades nas direções x, y e z, respectivamente.

Fox et al. (2010) também apresentaram as equações de conservação da quantidade de movimento para escoamentos permanentes, incompressíveis e com viscosidade constante, as quais estão representadas nas Equações $8 \mathrm{a}, 8 \mathrm{~b}$ e $8 \mathrm{c}$.

$\rho\left(u \frac{\partial u}{\partial x}+v \frac{\partial u}{\partial y}+w \frac{\partial u}{\partial z}\right)=\rho g_{x}-\frac{\partial p}{\partial x}+\mu\left(\frac{\partial^{2} u}{\partial x^{2}}+\frac{\partial^{2} u}{\partial y^{2}}+\frac{\partial^{2} u}{\partial z^{2}}\right)$

$\rho\left(u \frac{\partial v}{\partial x}+v \frac{\partial v}{\partial y}+w \frac{\partial v}{\partial z}\right)=\rho g_{y}-\frac{\partial p}{\partial y}+\mu\left(\frac{\partial^{2} v}{\partial x^{2}}+\frac{\partial^{2} v}{\partial y^{2}}+\frac{\partial^{2} v}{\partial z^{2}}\right)$

$\rho\left(u \frac{\partial w}{\partial x}+v \frac{\partial w}{\partial y}+w \frac{\partial w}{\partial z}\right)=\rho g_{z}-\frac{\partial p}{\partial z}+\mu\left(\frac{\partial^{2} w}{\partial x^{2}}+\frac{\partial^{2} w}{\partial y^{2}}+\frac{\partial^{2} w}{\partial z^{2}}\right)$ 
Nos casos estudados, em termos de macroescala, a conservação da massa pode ser traduzida pela consideração de que a vazão volumétrica de injeção é igual à soma da vazão volumétrica do fluido através do conjunto dos furos e da seção transversal da região do dedão.

As condições de contorno são do tipo Dirichlet, com velocidade prescrita no plano de entrada e fixação de pressão na saída da tubulação e dos furos, de acordo com a Figura 6. Na entrada $(x=0)$ tem-se a fixação da velocidade $V_{\text {med }}=0,005 \mathrm{~m} / \mathrm{s}$, que depende de cada cenário, enquanto que na saída principal $(x=L)$, o qual representa o dedão do liner, tem-se a pressão $P_{t u b}(L)=0$. Nos furos, a pressão de saída radial $\left(P_{\text {furos }}(x)\right)$ também é igual a zero.

Figura 6 - Condições de contorno utilizadas no problema.

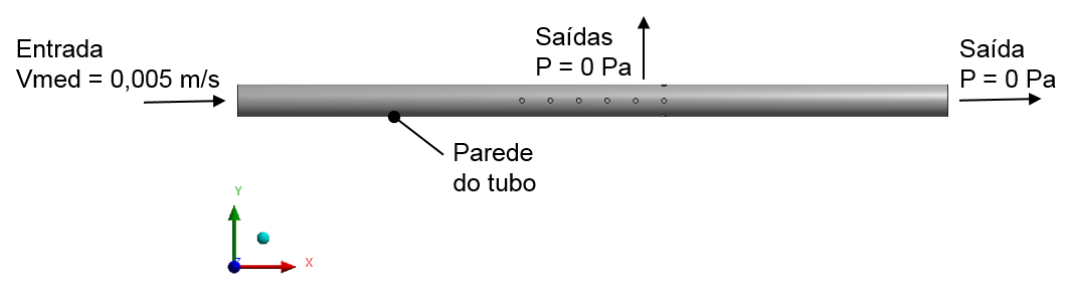

Fonte: Autores (2019).

$\mathrm{Na}$ parede interna da tubulação, que é fixa, as condições de contorno seguem os princípios de não deslizamento e de impenetrabilidade, os quais garantem que a velocidade do escoamento nesta região é igual a zero e que nenhuma quantidade de fluido a atravessa.

\subsection{Abordagem numérica}

Foram utilizados os softwares comerciais da família Ansys v. 15.0, instalados nos computadores do Laboratório de Simulação Numérica da Engenharia de Petróleo (Labsim) da Universidade Federal do Espírito Santo (UFES). A geometria apresentada na Figura 5 foi discretizada no módulo Mesh. O teste de independência de malha foi realizado utilizando quatro malhas para as condições do cenário 4 com viscosidade $20 \mathrm{mPa}$.s (Tabela 2).

Tabela 3 - Detalhamento do nível de refinamento da malha.

\begin{tabular}{|c|c|c|}
\hline Malha & Número de elementos & Tempo, min \\
\hline 1 & 203.860 & 4,03 \\
\hline 2 & 486.840 & 16,83 \\
\hline 3 & 653.506 & 28,2 \\
\hline 4 & 839.446 & 42,57 \\
\hline
\end{tabular}

Para garantir o escoamento desenvolvido na entrada da tubulação, foi imposta a equação $u(r)=U\left[1-(r / R)^{2}\right]$ (Fox, Pritchard \& McDonald, 2010) mediante a opção userdefined function (UDF) do software. A UDF requer como dados de entrada a velocidade média do escoamento $(U)$ na entrada e o diâmetro $(2 R)$ da tubulação. 
Res., Soc. Dev. 2019; 8(9):e50891327

ISSN 2525-3409 | DOI: http://dx.doi.org/10.33448/rsd-v8i9.1327

O parâmetro avaliado neste teste foi a variação da vazão ao longo do comprimento da tubulação, traduzido como a distância a partir do calcanhar. O gráfico dos resultados obtidos para as quatro malhas avaliadas é apresentado na Figura 7.

Figura 7 - Resultados obtidos para o teste de independência de malha.

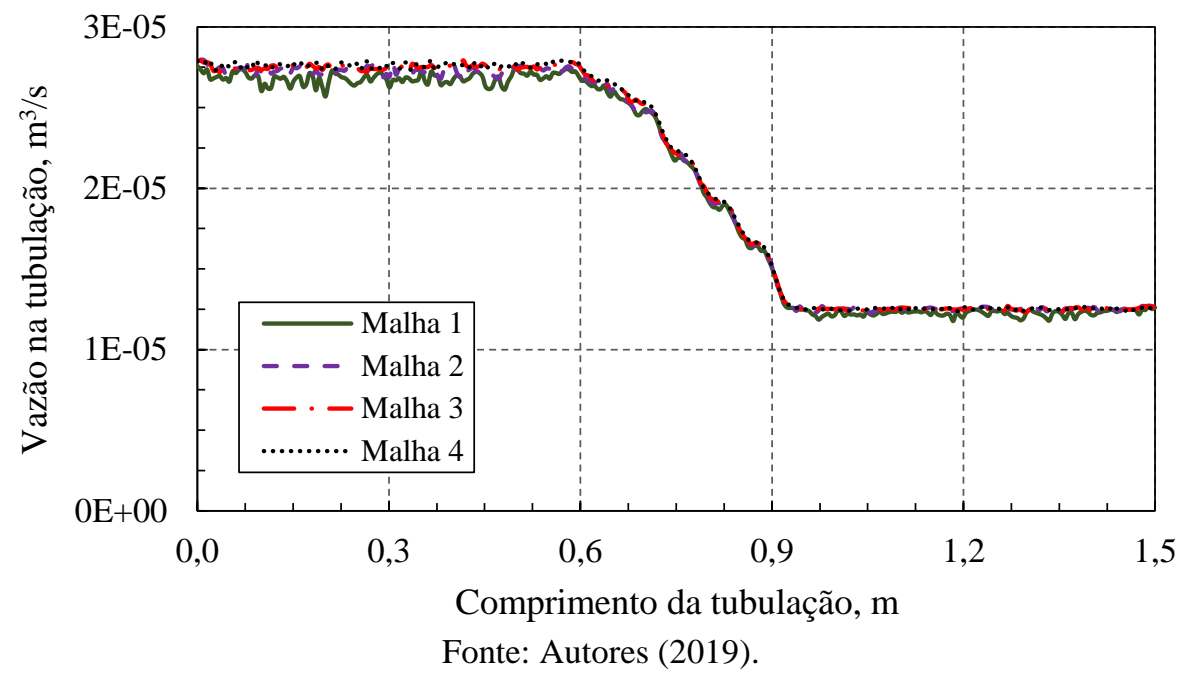

Após a análise do gráfico gerado para o teste de independência de malha, concluiu-se que a malha 2 é a mais adequada para a realização das simulações referentes a este estudo, pois apresenta tempo computacional e resultados de pressão satisfatórios, coincidindo, em diversos pontos, com as curvas das malhas 3 e 4. Por outro lado, a malha 1 apresentou discrepância significativa na variação da vazão.

A solução das equações foi mediante o método de solução baseado na pressão do Fluent. Segundo o Ansys (2013), este método foi desenvolvido para escoamentos incompressíveis e com velocidade de baixa magnitude.

O acoplamento entre pressão e velocidade foi realizado pelo solver através da equação de fluxo para cada face do elemento, derivando-se uma condição adicional para a pressão até que a equação da continuidade seja satisfeita. Isto ocorreu de forma segregada neste estudo, com a utilização do algoritmo SIMPLE, que utiliza uma relação entre as correções de pressão e de velocidade no elemento para garantir a continuidade e para obter o campo de pressões (Ansys, 2013).

A continuidade deve ser garantida em cada elemento da malha do domínio estudado, até que o somatório do produto entre o fluxo em cada face do elemento e a área desta face seja igual a zero. Usualmente, o solver utiliza um valor de tolerância próximo de zero para a convergência, denominado resíduo, considerando a dificuldade da resolução de problemas de escoamento e a limitação do software. Neste estudo, o resíduo foi definido igual a $10^{-4}$. 
ISSN 2525-3409 | DOI: http://dx.doi.org/10.33448/rsd-v8i9.1327

Outro parâmetro importante é o tipo de inicialização da solução. Neste estudo, foi utilizada a inicialização híbrida, a qual o Ansys (2013) define como um conjunto de fórmulas e métodos de interpolação que resolvem a equação de Laplace para produzir campos de velocidade e de pressão, que, respectivamente, estejam em conformidade com geometrias de domínio complexo e conectem suavemente valores discrepantes de pressão no domínio computacional.

\section{Resultados e comentários}

Foi avaliada a queda de pressão, vazão e fluxo nos furos ao longo da tubulação para valores de viscosidade crescentes (cenários de 1 a 5 da Tabela 2). Os gráficos cartesianos são os resultados do Fluent pós processados no ambiente Excel-MS.

Na Figura 8 apresenta-se a comparação das curvas de gradiente de pressão. A curva do cenário 5, sem furos, tem uma redução linear da pressão, isto é, gradiente de pressão constante. O cenário 4, que é diferente do 5 apenas na presença dos furos, apresenta igual gradiente de pressão na região antes dos furos. Após os furos (região C) o gradiente de pressão é menos acentuado devido à que, conforme evidenciado na Figura 9, menos fluido está presente no interior da tubulação. Desta forma, é necessário menos energia para movimentar o líquido viscoso remanescente da perda através dos furos.

Figura 8 - Variação da pressão na linha de centro da tubulação para diversas viscosidades do fluido injetado.

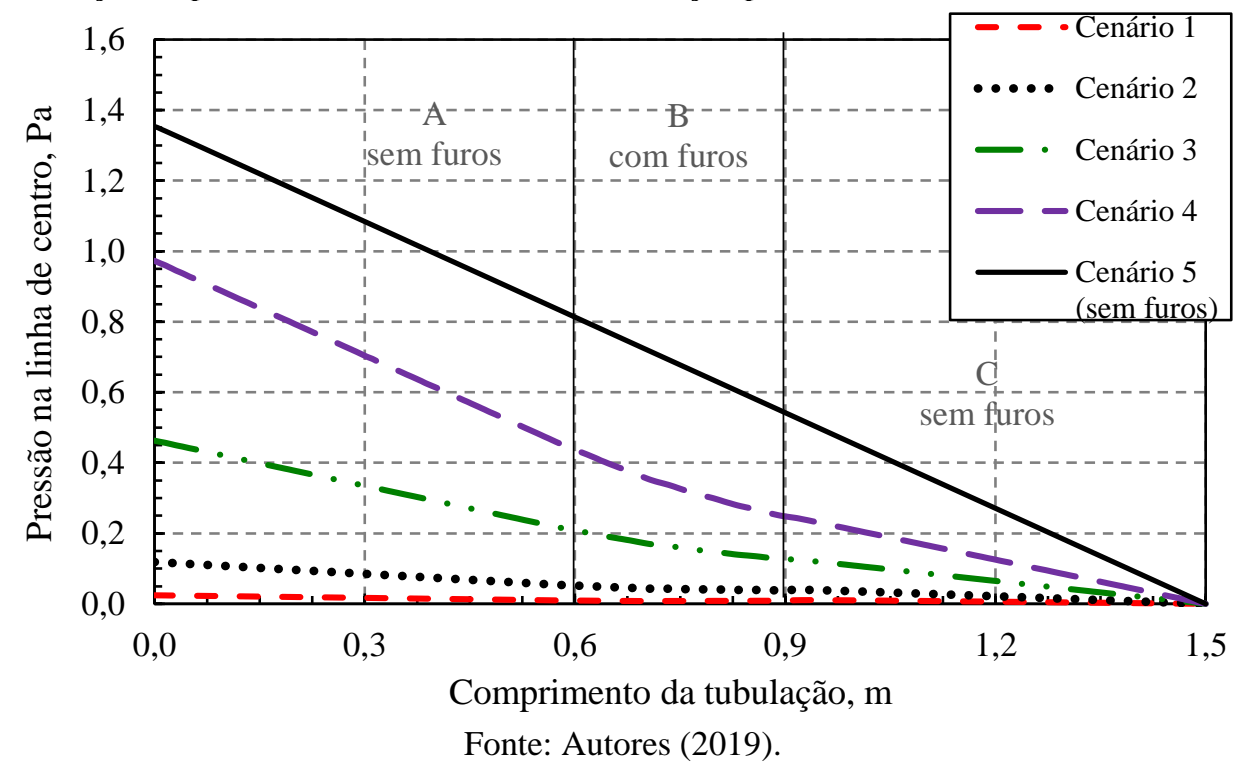

Analisando ainda os resultados da Figura 8, tem-se que para os cenários 3, 2 e 1, projetados com redução gradativa da viscosidade do líquido bombeado (Tabela 2), 
apresentam gradiente de pressão cada vez menos acentuado, o que é compatível com a condição de menos resistência, oriunda da viscosidade, oferecida pelos fluidos.

Complementado as observações da Figura 9 tem-se que o cenário 5, sem furos, apresentou como esperado, vazão constante é igual a $2,79 \times 10^{-5} \mathrm{~m}^{3} / \mathrm{s}$, ao longo de toda a tubulação. No cenário 4, a vazão decresce no trecho B devido à presença dos furos pelos quais o fluido escoa para o ambiente externo. Já nos trechos A e C que não contem furos neste cenário 4 , as vazões são constantes, sendo a vazão escoada pelos furos igual a $1,54 \times 10^{-5} \mathrm{~m}^{3} / \mathrm{s}$, $55,2 \%$ da vazão inicial.

Figura 9 - Vazão na tubulação para os cenários 4 (com furos) e 5 (sem furos).

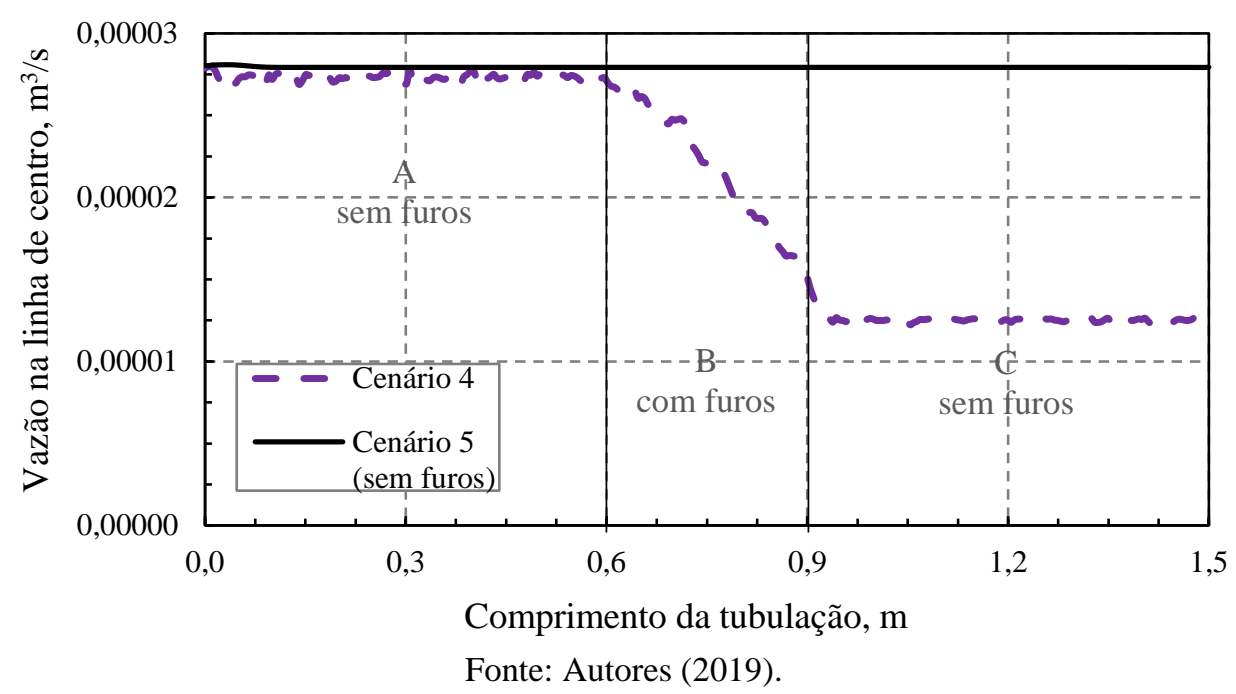

Em geral, o aumento da viscosidade fez com que a perda de pressão aumentasse (Figura 8) o que é justificado pela Equação 6. O perfil de pressão nos trechos $\mathrm{A}$ e $\mathrm{C}$ apresentou decréscimo constante para todos os cenários analisados. Esta tendência é alterada no trecho B uma vez que o número de furos dispostos de forma crescente no sentido do escoamento, tornam a resposta não linear, com o perfil de pressão tornando-se mais abaulado com a redução da viscosidade do fluido. Como consequência disso a configuração do perfil de fluxo através dos furos no trecho B é também alterado, tendendo a ser mais uniforme com tendência abaulada clara para o fluido com menor viscosidade representado pelo cenário1, conforme mostra a Figura 10. Este comportamento está de acordo com o fenômeno descrito por Ozkan et al. (1999), que relataram o aumento da influência dos efeitos hidráulicos com o aumento do Reynolds previsto pela Equação 4. Com o aumento da viscosidade e consequente diminuição do Reynolds, nos cenários 2 a 4, o perfil adquiriu formato cada vez mais inclinado e menos uniforme, seguindo a tendência da pressão no trecho A. 
Res., Soc. Dev. 2019; 8(9):e50891327

ISSN 2525-3409 | DOI: http://dx.doi.org/10.33448/rsd-v8i9.1327

Os vetores de velocidade ao longo da tubulação para os cenários 1 a 4, podem ser observados na Figura 11. O aumento da viscosidade do fluido injetado exerceu influência significativa na velocidade. As forças viscosas aumentaram do cenário 1 ao 4 , deixando o escoamento no interior da tubulação mais lento e fazendo com que a tendência ao fluxo reverso nos furos diminuísse. No interior do tubo, para o cenário 1, a velocidade praticamente não se alterou, diferentemente do que ocorreu nos cenários 2 a 4, nos quais o perfil de fluxo através dos furos se transformou consideravelmente.

Figura 10 - Perfis de fluxo através dos furos de cada plano para os cenários 1 a 4.

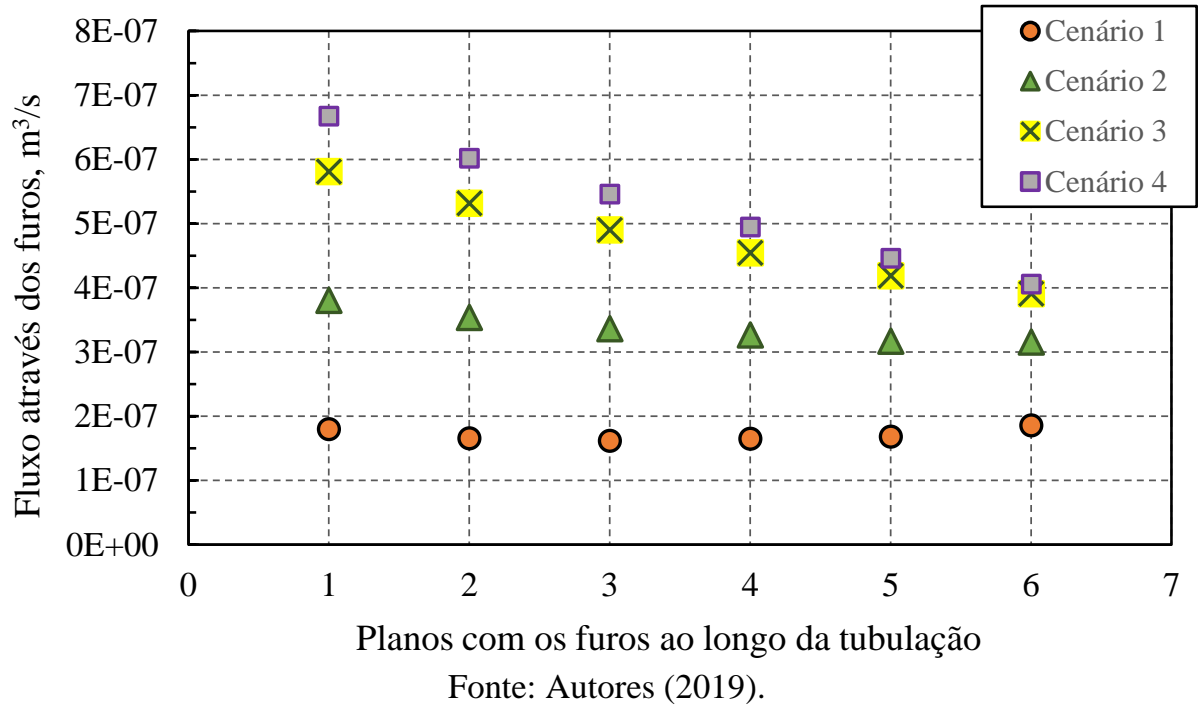

Figura 11 - Vetores de velocidade ao longo da tubulação e através dos furos para os cenários 1 a 4.

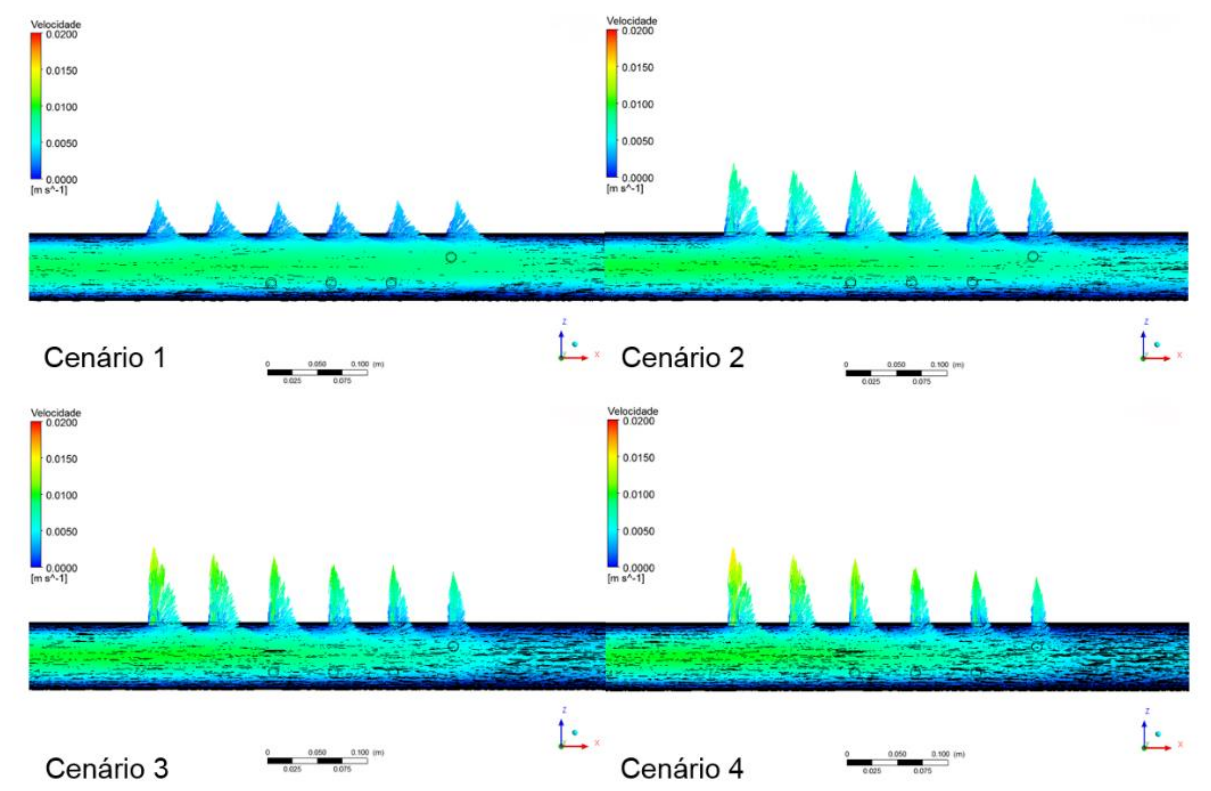

Fonte: Autores (2019).

\section{Conclusões}


Res., Soc. Dev. 2019; 8(9):e50891327

ISSN 2525-3409 | DOI: http://dx.doi.org/10.33448/rsd-v8i9.1327

Neste trabalho é apresentado a simulação numérica do processo de injeção de fluidos em uma tubulação horizontal com diâmetro constante e na presença de diversos furos alocados na sua superfície. As condições avaliadas permitem destacar as seguintes conclusões:

a) o domínio das forças inerciais nos cenários com menor viscosidade, traduzido pelos números de Reynolds mais altos, acarretaram em perfis de fluxo mais uniformes e, por consequência, maior injetividade, enquanto que os cenários nos quais as forças viscosas dominam, ou seja, com Reynolds baixo, se assemelharam à curva de pressão do tubo sem furos, com baixa influência dos efeitos hidráulicos;

b) embora o tamanho reduzido da geometria utilizada para representar a tubulação (liner) e o número de furos menores do que os utilizados em campo, os resultados do trabalho permitem demonstrar que existe coerência com o comportamento apresentado na literatura. Isto é, a furação diversiva tende a uniformizar a perfil de fluxo através dos furos;

c) a presença dos furos na tubulação alivia o gradiente de pressão na região pós furos, uma vez que a velocidade do fluido é reduzida resultando em menor atrito e menor perda de carga;

d) o gradiente de pressão antes dos furos é maior do que na região depois dos furos, o qual é justificado pela menor velocidade dos fluidos no trecho depois dos furos;

e) a perda de carga aumenta na medida que o fluido torna-se mais viscoso. Este comportamento implica em gradientes de pressão mais acentuados.

\section{Referências}

Amaral, A. S., Augustine, J. R., Henriksen, K. H., Rodrigues, V. F., Steagall, D. E., Paixão, L. C., \& Barbosa, V. P. (2008). Equalization of the water injection profile of a subsea horizontal well: a case history. Proceedings of the SPE International Symposium and Exhibition on Formation Damage Control, Lafayette, United States of America. Paper 112283.

ANP (2017). Relatório do seminário sobre aumento do fator de recuperação no Brasil. Recuperado de http://www.anp.gov.br/images/Palestras/Aumento_Fator_Recuperacao/Relatorio_do_Seminar io_sobre_Aumento_do_Fator_de_Recuperacao_ANP.pdf 
ANSYS (2013). Ansys Fluent theory guide.

Art of Directional Drilling (2015). Types of directional well profiles. Recuperado de https://directionaldrillingart.blogspot.com/2015/09/types-of-directional-well-profiles-in.html

Bertulani, C. (1999). Propriedades de fluidos. Recuperado de http://www.if.ufrj.br/ bertu/fis2/hidrostatica/tabela_LIQ.html

British Petroleum. (2018). BP statistical review of world energy. Recuperado de https://www.bp.com/content/dam/bp/en/corporate/pdf/energy-economics/statisticalreview/bp-stats-review-2018-full-report.pdf

Brito, E. E. F. (2008). Análise da trajetória de poços horizontais em reservatório de óleo pesado (Dissertação de Mestrado). Universidade Federal do Rio Grande do Norte, Natal, RN, Brasil. Recuperado de https://repositorio.ufrn.br/jspui/handle/123456789/12932

Cajazeiras, V. C. (2018). Estudo de perfil de escoamento monofásico de um sistema injetor de água em campos de petróleo por simulações estacionárias (Trabalho de conclusão de curso). Universidade Federal Fluminense, Niterói, RJ, Brasil. Recuperado de https://app.uff.br/riuff/bitstream/1/7074/1/TCC\%20Vinicius\%20Cupello\%20Cajazeiras.pdf

Dikken, B. J. (1989). Pressure drop in horizontal wells and its effect on production performance. Proceedings of the SPE Annual Technical Conference and Exhibition, San Antonio, United States of America. Paper 19824.

Fernandes, P. D., Silva, M. G. F., \& Bedrikovetsky, P. (2006). Uniformização de escoamento em poços horizontais. Boletim técnico da produção de petróleo, 1(1), 139-156. Recuperado de http://www.pbpublishing.com.br/uploads/PublishedContent/BPPT/V1/V1N1/V1N1P139156.pdf

Fox, R. W., Pritchard, P. J., \& McDonald, A. T. (2010). Introdução à mecânica dos fluidos. Rio de Janeiro: LTC. 
Res., Soc. Dev. 2019; 8(9):e50891327

ISSN 2525-3409 | DOI: http://dx.doi.org/10.33448/rsd-v8i9.1327

Guilhermino, B. A. C. (2013). Estudo da produtividade de poços horizontais (Trabalho de conclusão de curso). Universidade Federal Fluminense, Niterói, RJ, Brasil. Recuperado de https://app.uff.br/riuff/handle/1/1434

Hansen, J. H., \& Nederveen, N. (2002). Controlled acid jet (CAJ) technique for effective single operation stimulation of $14000+f t$ long reservoir sections. Proceedings of the SPE European Petroleum Conference, Aberdeen, Scotland, 9. Paper 78318.

Inglis, T. A. (1987). Directional drilling. Londres: Graham \& Trotman.

Joshi, S. D. (1991). Horizontal well technology. Oklahoma: Pennwell.

Landman, M. J., \& Goldthorpe, W. H. (1991). Optimization of perforation distribution for horizontal wells. Proceedings of the SPE Asia-Pacific Conference, Perth, Australia. Paper 23005.

Oliveira, R. (2011). Study of the horizontal wellbore and reservoir coupling. Proceedings of the SPE Annual Technical Conference and Exhibition, Denver, United States of America. Paper 1152372.

Oliveira, T. J. L., Magalhães, J. V. M., \& Martins, A. L. (2006). Aplicação de um simulador computacional de gravel pack em poços horizontais equipados com telas diversivas. Anais do Brazilian Congress of Thermal Sciences and Engineering, Curitiba, Brasil, 11.

Ozkan, E., Sarica, C., \& Haci, M. (1993). Influence of pressure drop along the wellbore on horizontal-well productivity. Proceedings of the SPE Production Operations Symposium, Oklahoma, United States of America. Paper 57687.

Penmatcha, V. R., Arbabi, S., \& Aziz, K. (1997). Effects of pressure drop in horizontal wells and optimum well lenght. Proceedings of the SPE Production Operations Symposium, Oklahoma, United States of America. Paper 57193. 
Res., Soc. Dev. 2019; 8(9):e50891327

ISSN 2525-3409 | DOI: http://dx.doi.org/10.33448/rsd-v8i9.1327

Petrobras. (2014). Relatório de tecnologia Petrobras 2013. Recuperado de http://www.petrobras.com.br/lumis/portal/file/fileDownload.jsp?fileId=8A8B2D164F32A6C1 014FF50A6A817AB9

Rosa, J. V. (2017). Análise dos efeitos da queda de pressão em poços horizontais na produção de campos de petróleo (Dissertação de Mestrado). Universidade Estadual de Campinas, Campinas, SP, Brasil. Recuperado de http://repositorio.unicamp.br/bitstream/REPOSIP/330515/1/Rosa_JoaoVictor_M.pdf

Santos, L. A. (2014). Investigação das perdas de carga na técnica de furação diversiva para poços horizontais (Trabalho de conclusão de curso). Universidade Federal do Espírito Santo, São Mateus, ES, Brasil.

Silva, R. (2017). Método numérico, analítico e experimental: concorrentes ou complementares na engenharia? Recuperado de https://www.esss.co/blog/metodo-numericoanalitico-e-experimental-concorrentes-ou-complementares-na-engenharia/

Vale, B. T. (2010). Análise da variação de pressão no escoamento unidimensional no interior de poços horizontais (Trabalho de conclusão de curso). Universidade Federal de Santa Catarina, Florianópolis, SC, Brasil. Recuperado de http://www.sinmec.ufsc.br/site/arquivos/iieubdfzlcz_trabalho_de_conclusao_bruno_terencio_do_vale.pdf

Vicente, R., Sarica, C., \& Ertekin, T. (2003). Horizontal well design optimization: a study of the parameters affecting the productivity and flux distribution of a horizontal well. Proceedings of the SPE Annual Technical Conference and Exhibition, Denver, United States of America. Paper 84194.

\section{Porcentagem de contribuição de cada autor no manuscrito}

Isabela Silva Mantegazini - 50\%

Oldrich Joel Romero - 50\% 